\title{
Metformin: a review of its potential indications
}

This article was published in the following Dove Press journal:

Drug Design, Development and Therapy

22 August 2017

Number of times this article has been viewed

\section{Yi-Wei Wangl,* \\ $\mathrm{Si}$-Jia $\mathrm{He}^{1, *}$ \\ Xiao Feng' \\ Jin Cheng' \\ Yun-Tao Luo' \\ Ling Tian ${ }^{2}$ \\ Qian Huang'}

'The Comprehensive Cancer Center and Shanghai Key Laboratory for

Pancreatic Diseases, Shanghai General Hospital, Shanghai Jiao Tong University

School of Medicine, Shanghai, People's

Republic of China; ${ }^{2}$ Institute of

Translational Medicine, Shanghai

General Hospital, Shanghai Jiao

Tong University School of Medicine,

Shanghai, People's Republic of China

*These authors contributed equally to this work
Correspondence: Qian Huang

The Comprehensive Cancer Center and Shanghai Key Laboratory for Pancreatic Diseases, Shanghai General Hospital, Shanghai Jiao Tong University School of Medicine, No 650, Xin Song Jiang Road, Shanghai 201620, People's Republic of China

Tel +86 2l 37798906

Email qhuang@sjtu.edu.cn
Abstract: Metformin is the most commonly prescribed drug for type 2 diabetes mellitus. In recent years, in addition to glucose lowering, several studies have presented evidence suggesting some potential role for metformin, such as antitumor effect, antiaging effect, cardiovascular protective effect, neuroprotective effect or an optional treatment for polycystic ovary syndrome. This paper will critically review the role of metformin to provide reference for doctors and researchers.

Keywords: metformin, antitumor effect, antiaging effect, cardiovascular protective effect, neuroprotective effect, PCOS

\section{Introduction}

Metformin has become one of the most widely used drugs in the treatment of type 2 diabetes mellitus (T2DM) since its approval in the United Kingdom in 1958 and in the United States in 1995 , with doses ranging from 500 to $2,500 \mathrm{mg} /$ day. ${ }^{1}$ It is the first-line therapy for patients with T2DM according to the American Diabetes Association/European Association for Study of Diabetes guidelines. ${ }^{2}$ Metformin works by decreasing intestinal glucose absorption, improving peripheral glucose uptake, lowering fasting plasma insulin levels and increasing insulin sensitivity, which result in a reduction of blood glucose concentrations without causing overt hypoglycemia. ${ }^{3}$ Additionally, metformin can inhibit gluconeogenesis with the activation of AMPactivated protein kinase (AMPK). ${ }^{4}$ AMPK is an important player in the regulation of energy metabolism, which plays a key role in diabetes and related metabolic diseases. It is demonstrated that AMPK is required for maintaining glucose homeostasis. ${ }^{5}$ Metformin has few adverse side effects, the most common adverse side effects being gastrointestinal symptoms (incidence rate $20 \%-30 \%$ ), including nausea and vomiting, ${ }^{6}$ and the most serious adverse effects being lactic acidosis (incidence rate 1/30,000), mainly in diabetic patients with liver and kidney dysfunction. ${ }^{7}$

Since metformin's worldwide spread for over 50 years, numerous studies concerning other potential indications have emerged, which showed that metformin can also be used as an anticancer agent, ${ }^{8}$ an antiaging agent, ${ }^{9}$ a cardiovascular protective agent, ${ }^{10} \mathrm{a}$ neuroprotective agent ${ }^{11}$ or an optional drug for polycystic ovary syndrome (PCOS). ${ }^{12}$ In this review, we summarized the currently potential indications and possible mechanism of metformin, and expect many more studies for further verification.

\section{Antitumor effect of metformin}

Metformin was first discovered as an antitumor agent on hamsters in 2001. In this experiment, there were two groups of high-fat (HF)-fed hamsters. One group received metformin in drinking water for life (HF + Met group), and the other group served as the control group (HF group). All hamsters were treated with N-nitrosobis-(2-oxopropyl) 
amine, a pancreatic carcinogen, and after 42 weeks, 50\% of the hamsters in the high-fat group developed malignant lesions; however, none was found in the $\mathrm{HF}+$ Met group $(P<0.05) .{ }^{13}$ A large case-control study in Scotland first showed that metformin reduced the risk of cancer in patients with T2DM (odds ratio [OR] 0.77, 95\% CI 0.64-0.92 for any metformin exposure versus no metformin exposure). ${ }^{14}$ A representative population prospective cohort study of 800,000 individuals showed that metformin reduced the incidences of several gastroenterological cancers in treated diabetes (total $0.12(0.08-0.19)$, colorectal $0.36(0.13-0.98)$, liver $0.06(0.02-0.16)$, pancreas $0.15(0.03-0.79))$, the dose of metformin is shown in Table $1 .{ }^{15}$ In addition to the reduction of cancer incidence, ${ }^{16,17}$ metformin intake was also associated with a decrease of cancer mortality. Landman et al showed that metformin was associated with lower cancer mortality (hazard ratio [HR] $0.43[0.23-0.80]$ ) and that the effect was dose dependent (Table 1). ${ }^{18} \mathrm{~A}$ recent metaanalysis concluded that metformin reduced cancer incidence and mortality in patients with diabetes, with overall cancer incidence reduced by $31 \%$ and cancer mortality reduced by $34 \% .{ }^{8}$ Furthermore, a meta-analysis ${ }^{19}$ suggested that metformin had the greatest benefits as an adjuvant agent in colorectal and prostate cancer treatment, particularly in those receiving radiotherapy. However, the dose of metformin needs to be further explored. So far, several epidemiologic studies have reported the antitumor effect of metformin in different tumors, such as ovarian, ${ }^{20,21}$ breast, ${ }^{22,23}$ prostate $^{24}$ and colorectal. ${ }^{25}$

However, some studies also considered that there was no significant effect of metformin on cancer risk, survival

Table I Summary of effective dose of metformin in studies

\begin{tabular}{|c|c|}
\hline $\begin{array}{l}\text { Antitumor effect of } \\
\text { metformin }\end{array}$ & $\begin{array}{l}500 \mathrm{mg} / \text { day }^{15} \\
\text { The greater the metformin exposure, } \\
\text { the stronger the risk reduction }{ }^{18}\end{array}$ \\
\hline Antiaging effect of metformin & $0.1 \%$ metformin in $\operatorname{diet}^{54}$ \\
\hline $\begin{array}{l}\text { Cardiovascular protective } \\
\text { effects of metformin }\end{array}$ & $\begin{array}{l}\text { Starting with one } 850 \mathrm{mg} \text { tablet } \\
\text { per day, then } 850 \mathrm{mg} \text { twice a day, } \\
\text { and then I,700 } \mathrm{mg} \text { in the morning } \\
\text { and } 850 \mathrm{mg} \text { with the evening meal } \\
\text { (maximum dose }=2,550 \mathrm{mg})^{56} \\
\mathrm{I} .4 \pm 0.2 \mathrm{~g}^{10}\end{array}$ \\
\hline $\begin{array}{l}\text { Neuroprotective effect of } \\
\text { metformin }\end{array}$ & $\begin{array}{l}\text { Starting with } 0.5 \mathrm{~g} \text { tablet, two tablets } \\
\text { a day with meals. If the blood glucose } \\
\text { level is not controlled for } 7 \text { days } \\
\text { after taking metformin, it should be } \\
\text { increased to } 1.5 \mathrm{~g} / \text { day over } 2 \text { weeks } \\
\text { (maximum dose }<2.0 \mathrm{~g} / \text { day) } \text { ) }^{85} \\
\text { I,000 mg twice a day } 86\end{array}$ \\
\hline Polycystic ovary syndrome & Range from 850 to $1,700 \mathrm{mg}$ \\
\hline
\end{tabular}

time and mortality risk of cancer in T2DM patients, such as lung cancer, ${ }^{26}$ breast cancer ${ }^{27}$ and prostate cancer. ${ }^{28} \mathrm{~A}$ recent study also reported that metformin has no protective association with survival in colorectal cancer patients with T2DM (HR 1.06, 95\% CI 0.80-1.40). ${ }^{29}$

Therefore, whether metformin has antitumor effect or not has attracted much attention. Accumulating evidence showed metformin's role in attenuating tumorigenesis. First, $\mathrm{Wu}$ et $\mathrm{al}^{30}$ uncovered that metformin's antitumor properties rely on two elements of a single genetic pathway - the nuclear pore complex (NPC), which allows the passage of molecules into and out of the nucleus, and an enzyme called acyl-CoA dehydrogenase family member-10 (ACAD10) (Figure 1). Basically, metformin's suppression of mitochondrial respiratory capacity reduces cellular energy, restricting transit of the RagA-RagCGTPase heterodimer through the NPC. This shuts off an important cellular growth molecule called mTORC1, and the inactivation of mTORC1 subsequently inhibits growth and extends the lifespan of Caenorhabditis elegans through transcriptional induction of ACAD10. Moreover, in human melanoma and pancreatic cancer cells, the investigators confirmed that application of biguanides restricted nuclear pore transit and induced ACAD10 expression. After all, the experiments showed that metformin can no longer block the growth of cancer cells, if we force the nuclear pore to remain open, or if we permanently close the ACAD10. This pathway provides a unified mechanism by which metformin can kill cancer cells and extend lifespan, and in specific environments, the nuclear pore and ACAD10 may be manipulated for the prevention or even treatment of certain cancers. Second, metformin can significantly reduce the risk factors of tumor in patients with T2DM, including glucose, insulin and insulin-like growth factor 1 (IGF-1). In order to create a fuel-rich environment for cancer progression, cancer cells usually uptake high levels of glucose. ${ }^{31}$ Metformin, as a glucose-lowering agent, can cut off supplies for cancer cells and inhibit tumor growth. ${ }^{32}$ Insulin and IGF-1 may act as potential growth factors capable of stimulating cell survival and mitogenesis, protecting cells from apoptosis to promote cancer development and progression..$^{31,33,34}$ This effect is mediated by the insulin receptor and the insulin-like growth factor 1 receptor (IGF-1R), which are expressed on many cancer cells,${ }^{35}$ through Ras/Raf/MEK/ERK signaling and PI3K/ Akt/mTORC1 signaling. ${ }^{36-38}$ Moreover, hyperinsulinemia has been shown to increase free or bioactive IGF-1 levels by the downregulation of insulin-like growth factor binding protein, resulting in the activation of IGF-1R. ${ }^{39}$ Metformin treatment can reduce the levels of insulin and IGF-1, thereby 


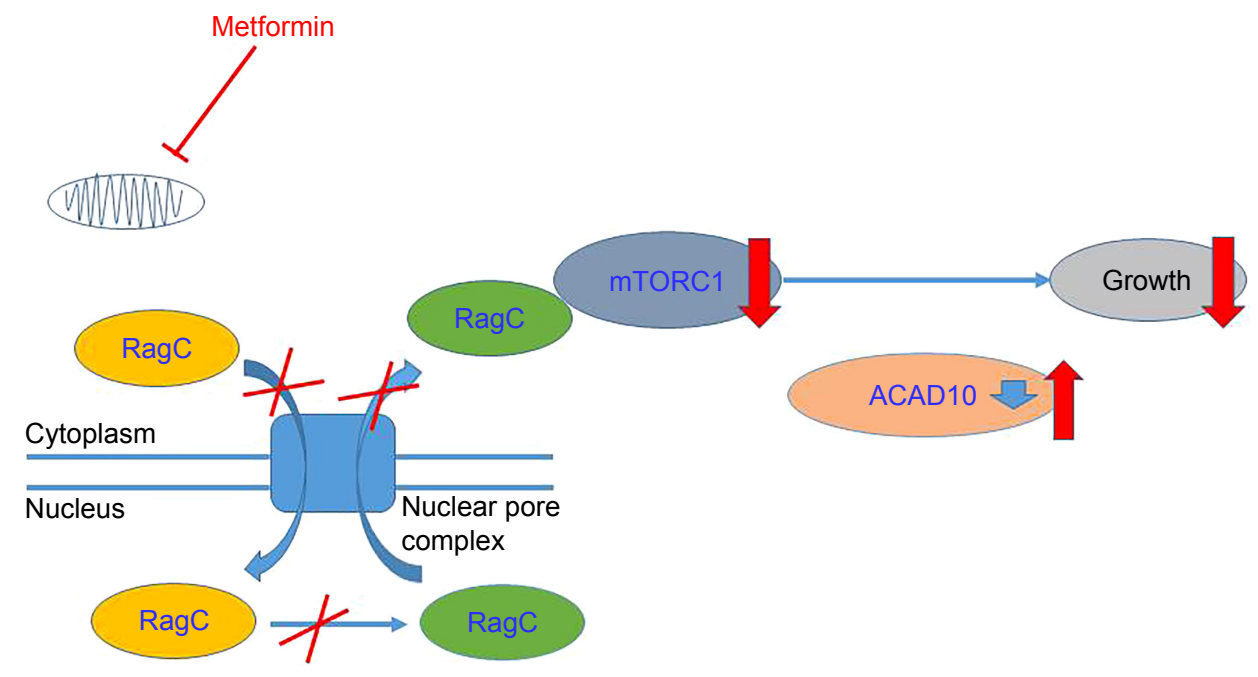

Figure I Model of the ancient pathway by which metformin extends lifespan and inhibits growth.

Notes: The figure shows that metformin's suppression of mitochondrial respiratory capacity reduces cellular energy, restricting transit of the RagA-RagCGTPase heterodimer through the NPC. Nuclear exclusion renders RagC incapable of gaining the guanosine diphosphate-bound state necessary to active mTORCI, subsequently inhibiting growth through transcriptional induction of ACADIO.

Abbreviations: NPC, nuclear pore complex; ACADI0, acyl-CoA dehydrogenase family member-10.

reducing the growth of cell. ${ }^{40}$ Third, activating the AMPK signaling pathway is also an important anticancer mechanism of metformin. The activated AMPK leads to energy preservation processes for cell survival at the expense of growth and proliferation. It can phosphorylate tuberous sclerosis complex 1 and 2, leading to the suppression of mTORC1 activation by inhibiting Ras homolog enrichment in brain (an mTORC1 activator). ${ }^{41-43}$ This inhibition of mTORC1 ultimately decreases protein synthesis and cell growth. ${ }^{36,44}$ Metformin can also inhibit mTORC1 by suppressing Rag GTPases $^{45}$ and upregulating the expression of REDD1 in a p53-dependent manner. ${ }^{46}$ Meanwhile, metformin has other AMPK-mediated actions that may be implicated in cancer, such as reduced lipogenesis, ${ }^{47,48}$ decreased angiogenesis, ${ }^{49}$ inhibition of the synthesis of proinflammatory cytokine ${ }^{50}$ and increase in the number of $\mathrm{CD} 8(+)$ tumor-infiltrating lymphocytes. ${ }^{51}$ Metformin's multiple tumor-relevant actions are depicted in Figures 1 and 2. However, most of the evidence for the treatment of metformin has been derived from retrospective cohort studies and case-control studies, instead of rigorous prospective or randomized controlled trials. There is still a lack of clinical evidence for metformin's antitumor activity in non-diabetic patients. Therefore, more clinical trials are needed to evaluate the role of metformin in different tumors.

\section{Antiaging effect of metformin}

Aging is a complex process, which is associated with accumulation of damage, loss of function and increased vulnerability to disease, ultimately leading to death. Human aging and agerelated diseases are becoming one of the greatest challenges and financial burdens faced by developed and developing countries. ${ }^{52}$ A growing body of evidence showed that metformin could delay aging and increase lifespan in vivo, specifically in nematodes and mice. Cabreiro et al found that metformin at 25, 50 and $100 \mathrm{mM}$ concentration increased mean lifespan by $18 \%, 36 \%$ and $3 \%$, respectively, in C. elegans. ${ }^{53}$ Martin-Montalvo et al showed that metformin increased lifespan by $4 \%-6 \%$ in different mouse breeds, and the long-term treatment with metformin $(0.1 \%$ metformin in diet) extended lifespan, while a higher dose ( $1 \%$ metformin) was toxic (Table 1).$^{54} \mathrm{~A}$ recent study determined that mean lifespan would be increased by $14 \%$ and maximum lifespan by 1 month if treatment with metformin is started early in life, but at older age, this effect would be declined. ${ }^{55}$ Additionally, there are also many studies that focus on whether antiaging effects of metformin can be demonstrated in patients with T2DM. In the United Kingdom Prospective Diabetes Study (UKPDS), the use of metformin decreased the risk of cardiovascular disease ${ }^{56}$ cancer incidence and overall mortality,${ }^{57}$ compared with other antidiabetic drugs. Furthermore, a large retrospective observational study including over 180,000 subjects showed that patients with T2DM initiated with metformin monotherapy had longer survival than did matched, non-diabetic controls; however, in this study they did not investigate for a dose-response association. ${ }^{9}$ On the contrary, Slack et a ${ }^{58}$ found that metformin can activate AMPK and reduce lipid stores, but cannot extend lifespan 

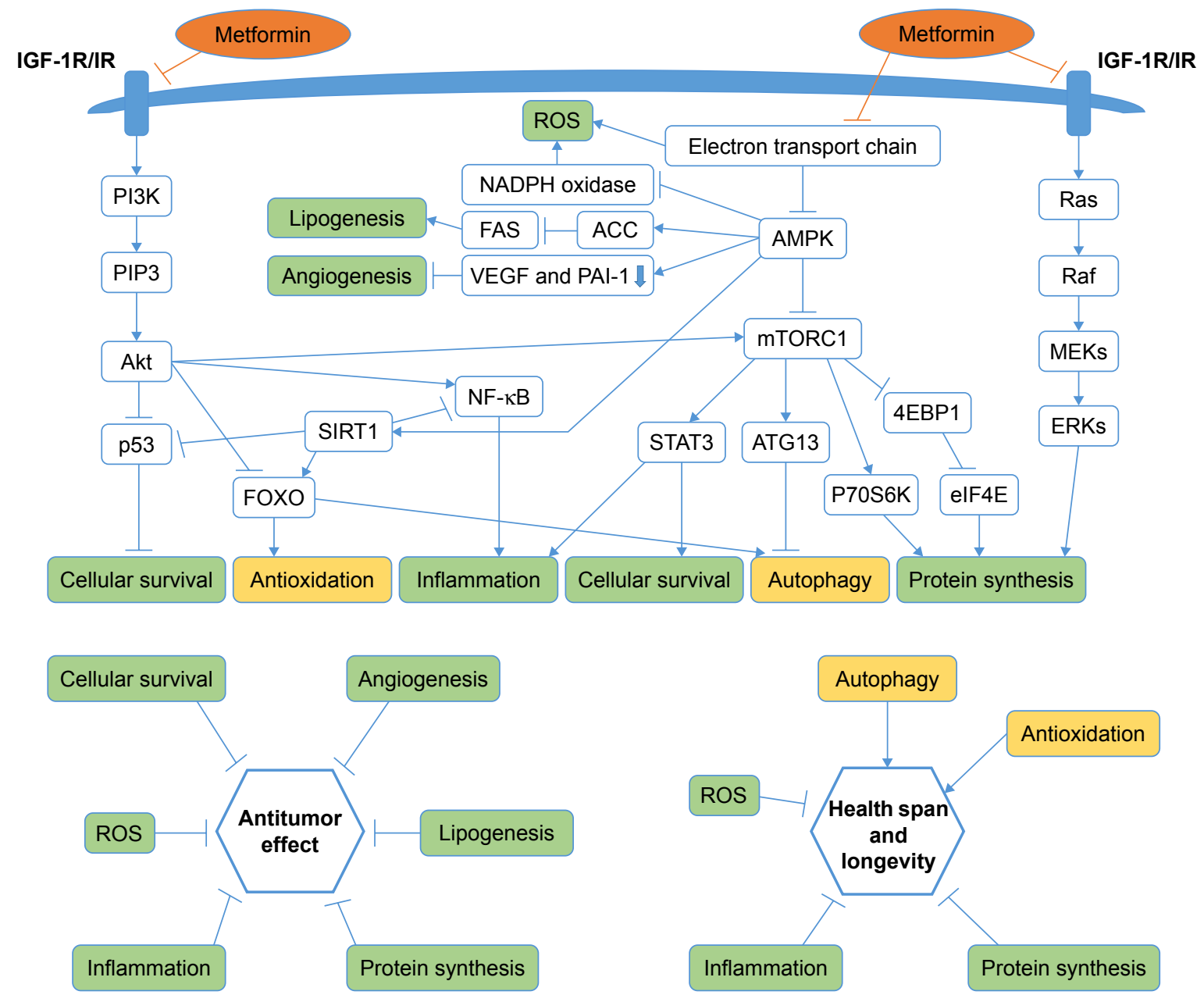

Figure 2 Metformin targets multiple pathways of oncogenesis and aging.

Notes: The figure schematically depicts the pathways that are important to target oncogenesis and aging, and indicates at which points metformin has been shown to have effects. These processes jointly affect cellular survival, antioxidation, inflammation, autophagy and protein synthesis, which are major biological outcomes associated with oncogenesis and aging/longevity. The green background means that metformin has a negative effect on the step. The yellow background means that metformin has an active effect on the step.

Abbreviations: IGF-IR, insulin-like growth factor I receptor; IR, insulin receptor; ROS, reactive oxygen species; AMPK, AMP-activated protein kinase.

in Drosophila (the final concentrations are 1, 2.5, 5, 10, 25, 50 and $100 \mathrm{nM})$. One possible reason is that the dose of metformin in the study is toxic. Similarly, a study confirmed that diet supplementation with $0.1 \%$ metformin led to a $5.83 \%$ extension of mean lifespan of C57BL/6 mice, while a higher concentration of metformin (1\%) was toxic and significantly shortened mean lifespan by $14.4 \%{ }^{54}$

Interventions that target aging-related pathways are capable of extending lifespan dramatically, especially health span, a period of life during which an individual is fully functional and free of chronic illness. ${ }^{59}$ These include intermittent or prolonged fasting, mild caloric restriction combined with a low glycemic index diet and protein restriction, inhibition of the GH/IGF-I axis, inhibition of TOR-S6K signaling, activation of sirtuins or AMPK and chronic metformin use. Metformin's multiple aging-relevant actions are also depicted in Figures 1 and 2. On one hand, as previously described, NPC and ACAD10 mediate biguanide-induced growth inhibition and lifespan extension. ${ }^{30}$ On the other hand, specifically for aging, metformin can not only decrease insulin and IGF-1 levels ${ }^{60}$ reduce the endogenous production of reactive oxygen species (ROS) $)^{61,62}$ and active AMPK, ${ }^{62-65}$ and inhibit mTOR, ${ }^{66,67}$ but also influence metabolic and cellular processes such as inflammation ${ }^{68}$ and autophagy. ${ }^{69}$ The United States intends to carry out a big clinical trial about the antiaging effect of metformin enrolling 3,000 non-diabetics aged $70-80$ years at roughly 15 centers. The follow-up will last for 5-7 years, and the situation of disease suffering and death after metformin treatment will be emphatically studied. The result of the clinical trial aimed to prove that metformin has a positive impact on human lifespan in non-diabetics and healthy people. 


\section{Cardiovascular protective effects of metformin}

Diabetic patients mainly die of cardiovascular complications, ${ }^{70}$ including macrovascular complications (such as stroke, coronary artery disease [CAD] and myocardial infarction) and microvascular complications (such as kidney disease, retinal injury and peripheral nerve disease), of which approximately $70 \%$ of all diabetic patients die of heart and brain macrovascular diseases. A number of clinical studies have shown that metformin has cardiovascular protective effects and reduces the incidence and mortality of cardiovascular events. In 1998, UKPDS, a randomized, prospective, multicenter trial, was the first trial to determine that metformin could significantly reduce the risk of all-cause mortality and acute myocardial infarction in overweight patients with T2DM; the dose of metformin is shown in Table $1 .{ }^{56}$ In addition, a 10 -year post-interventional follow-up of the UKPDS survivor cohort further examined that metformin treatment had a long-term benefit on cardiovascular risk in overweight patients. Compared with sulfonylurea and insulin treatment, metformin treatment can effectively reduce the risk of myocardial infarction and death. ${ }^{71}$ Similarly, Roumie et al also showed that compared with sulfonylurea therapy, metformin treatment was associated with a decreased hazard of cardiovascular disease events or death in T2DM. ${ }^{72}$ Moreover, data from the Reduction of Atherothrombosis for Continued Health Registry indicated that the use of metformin as a means of secondary prevention was associated with a $24 \%$ reduction in all-cause mortality after 2-year follow-up among patients with atherothrombosis. Thus, metformin has cardiovascular

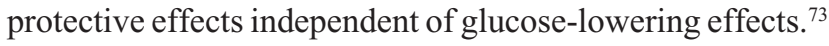
Furthermore, in a multicenter, randomized, double-blind, placebo-controlled clinical trial, Hong et al found that among type 2 diabetic patients with CAD, compared with glipizide, metformin treatment for 3 years (mean daily dose was $1.4 \pm 0.2 \mathrm{~g}$; Table 1) substantially reduced major cardiovascular events in a median follow-up of 5 years, which indicated a potential benefit of metformin treatment on cardiovascular outcomes in high-risk patients. ${ }^{10}$ After all, metformin is the only antidiabetic drug to be recommended by the 2013 AACE guidelines for cardiovascular benefit.

Metformin may exert beneficial effects to prevent cardiovascular disease. The risk factors of cardiovascular disease include dyslipidemia, obesity, hypertension, insulin resistance and so on. First, metformin may improve lipometabolism and reduce the level of LDL cholesterol by activation of AMPK. ${ }^{74}$ Second, metformin was associated with weight loss or less weight gain, ${ }^{75-77}$ the mechanism of which is thought to be the decreased perceived hunger resulting in diminished food intake. ${ }^{78}$ Third, a recent meta-analysis suggested that metformin could effectively lower systolic blood pressure in non-diabetic patients $;{ }^{79}$ possible mechanisms of blood pressure lowering by metformin include reduction of insulin resistance and plasma insulin, adrenergic receptor deactivation, reduction of intracytoplasmic calcium, inhibition of sympathetic drive especially in conditions of high dietary salt intake and increase of glomerular filtration rate and sodium excretion. ${ }^{80}$ In addition, metformin can alleviate oxidative stress and inflammatory response as well as improve endothelial cell function. ${ }^{81,82}$

\section{The neuroprotective effect of metformin}

Clinical studies concerning whether metformin could improve cognitive function and reduce the incidence of dementia in patients with T2DM are inconsistent. A Singapore Longitudinal Aging Study by Ng et al found that long-term treatment ( $>6$ years) with metformin among T2DM patients was significantly associated with lowest risk of cognitive impairment in both cross-sectional analysis (OR $0.30,95 \%$ CI $0.11-0.80$ ) and in longitudinal analysis (OR $0.27,95 \% \mathrm{CI} 0.12-0.60$ ). ${ }^{83}$ Herath et al also showed that metformin has better protective effect on domain of verbal learning, working memory and executive function, compared to other diabetic treatments. ${ }^{84}$ A small clinical trial by Guo et al found that the treatment with metformin for 24 weeks significantly improved cognitive performance and reduced depressive symptoms in T2DM patients with depression; the dose of metformin is shown in Table $1{ }^{85}$ Similarly, significant improvements can be found in subjects without treated diabetes with mild cognitive impairment after 12 months of metformin treatment (1,000 mg twice a day, Table 1). ${ }^{86}$ In addition, Cheng et al reported that T2DM patients with metformin have lower risk of dementia than those with other diabetes medications. ${ }^{11}$ Furthermore, it is reported that compared with no metformin use, 1 year, 2 years, 2-4 years, and $>4$ years of metformin exposure among elderly veterans with diabetes increased 7\% $(P=0.61)$ and decreased 29\% ( $P=0.08), 41 \%$ $(P=0.0026)$ and $84 \%(P<0.0001)$ risk of neurodegenerative diseases (ND), including Alzheimer, Huntington, Parkinson and dementia among elder adults, which concluded that the long-term metformin treatment has protective effect on the incidence of ND (American Diabetes Association, 2016). ${ }^{114}$ However, some studies have different results. A case-control study from the United Kingdom found that long-term use of metformin was associated with a slightly higher risk of $\mathrm{AD}$ 
(OR 1.71, 95\% CI 1.12-2.60). ${ }^{87}$ A recent Australian study suggested that T2DM patients treated with metformin had increased risk for impaired cognitive performance (OR 2.23, 95\% CI 1.05-4.75), but metformin users who were taking vitamin B12 and calcium may have alleviated metformininduced vitamin B12 deficiency and improved cognitive outcomes (OR 0.41, 95\% CI 0.91-0.92) ${ }^{88}$ Therefore, a larger trial seems warranted to evaluate the efficacy of metformin in neuroprotective effect.

Studies about the effect of metformin mostly focus on the $A \beta$ production and tau level. Metformin may decrease tau phosphorylation and total tau level, ${ }^{89,90}$ but its effect on $\mathrm{A} \beta$ production is still inconsistent. ${ }^{91,92}$ Besides, it is reported that AMPK play an important role in various $\mathrm{ND}^{93}$ the activation of AMPK via an AMPK activator (metformin) may be neuroprotective, via the enhancement of angiogenesis, neurogenesis and induction of autophagy. ${ }^{93-96}$ Metformin can also prevent brain mitochondrial dysfunction, decrease oxidative stress, increase brain-derived neurotrophic factor levels, ameliorate cognitive impairment and improve neurological deficits. ${ }^{97-100}$

\section{About PCOS}

PCOS is an endocrine and metabolic disorder found among women of reproductive age, which is characterized by hyperandrogenism, ovulatory dysfunction, altered LH/FSH ratio $(>2 / 3: 1)$, oligomenorrhea/amenorrhea and polycystic ovaries. ${ }^{101,102}$ Approximately $50 \%-70 \%$ of PCOS patients suffer from insulin resistance and resulting hyperinsulinemia. ${ }^{103-105}$ Patients with PCOS are predisposed to many complications such as cardiovascular and cerebrovascular diseases, hypertension, metabolic syndrome and T2DM. ${ }^{106-109}$ Metformin has been used for PCOS treatment since 1994, ${ }^{110}$ by which most of the metabolic abnormalities of PCOS can be reversed. ${ }^{111}$ Metformin dose ranged from 850 to $1,700 \mathrm{mg}$ in different studies (Table 1). The mechanism is thought to be mediated through increased insulin sensitivity, increased ovarian secretion of estrogen, decreased ovarian production of androgen and augmentation of the production of sex hormone binding globulin. ${ }^{111,112}$ A recent meta-analysis by Tang et al demonstrated that metformin can reduce testosterone and insulin in PCOS women. ${ }^{113}$

\section{Conclusion}

Metformin is the most commonly prescribed therapy for patients with T2DM. It has a good safety profile and is associated with low cost. With further exploration of the clinical effect and possible mechanism of metformin, its indications have been extended to antitumor effect, antiaging effect, cardiovascular protective effects, neuroprotective effects and an optional treatment for PCOS; the linkage of these effects is shown in Figure 3. Furthermore, many questions such as whether these potential indications of metformin can be observed in non-diabetics and whether genetic factors have an influence on the effect of metformin need to be clarified by substantial basic experiments and clinical trials.

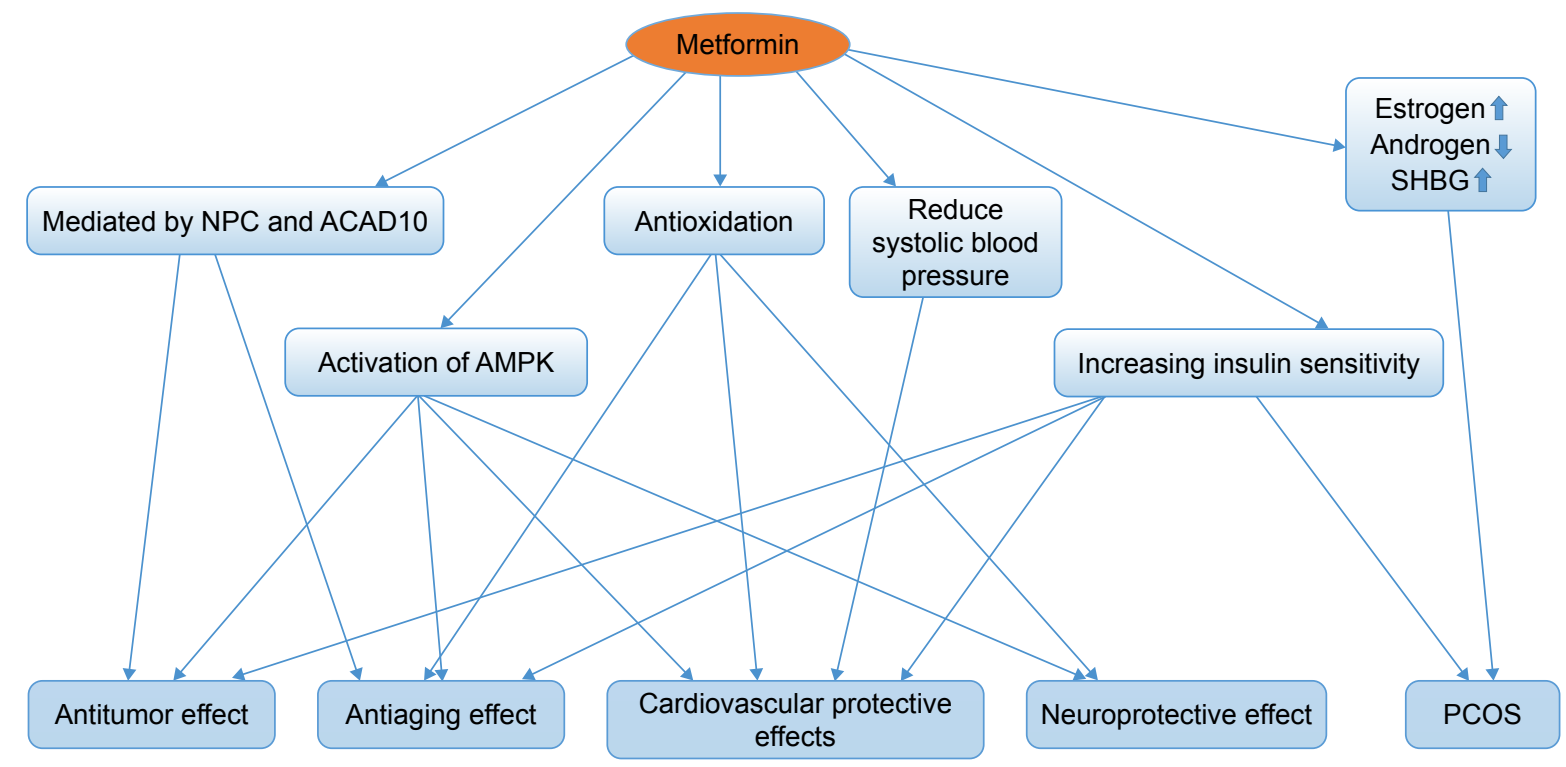

Figure 3 The linkage of the potential indications of metformin.

Abbreviations: NPC, nuclear pore complex; ACADI0, acyl-CoA dehydrogenase family member-10; AMPK, AMP-activated protein kinase; SHBG, sex hormone binding globulin; PCOS, polycystic ovary syndrome. 


\section{Acknowledgments}

We are thankful to the National Natural Science Foundation of China for funding (81120108017, 81572951 [Qian Huang] and 81502648 [Jin Cheng]).

\section{Disclosure}

The authors report no conflicts of interest in this work.

\section{References}

1. Scarpello JH, Howlett HC. Metformin therapy and clinical uses. Diab Vasc Dis Res. 2008;5(3):157-167.

2. Inzucchi SE, Bergenstal RM, Buse JB, et al. Management of hyperglycaemia in type 2 diabetes: a patient-centered approach. Position statement of the American Diabetes Association (ADA) and the European Association for the Study of Diabetes (EASD). Diabetologia. 2012; 55(6): 1577-1596.

3. Grzybowska M, Bober J, Olszewska M. Metformin - mechanisms of action and use for the treatment of type 2 diabetes mellitus. Postepy Hig Med Dosw (Online). 2011;65:277-285.

4. Matthaei S, Greten H. Evidence that metformin ameliorates cellular insulin-resistance by potentiating insulin-induced translocation of glucose transporters to the plasma membrane. Diabete Metab. 1991;17(1 Pt 2): $150-158$.

5. Zhang BB, Zhou G, Li C. AMPK: an emerging drug target for diabetes and the metabolic syndrome. Cell Metab. 2009;9(5):407-416.

6. Diabetes Prevention Program Research Group. Long-term safety, tolerability, and weight loss associated with metformin in the Diabetes Prevention Program Outcomes Study. Diabetes Care. 2012;35(4):731-737.

7. Salpeter S, Greyber E, Pasternak G, Salpeter E. Risk of fatal and nonfatal lactic acidosis with metformin use in type 2 diabetes mellitus. Cochrane Database Syst Rev. 2006;1:CD002967.

8. Gandini S, Puntoni M, Heckman-Stoddard BM, et al. Metformin and cancer risk and mortality: a systematic review and meta-analysis taking into account biases and confounders. Cancer Prev Res (Phila). 2014; 7(9):867-885.

9. Bannister CA, Holden SE, Jenkins-Jones S, et al. Can people with type 2 diabetes live longer than those without? A comparison of mortality in people initiated with metformin or sulphonylurea monotherapy and matched, non-diabetic controls. Diabetes Obes Metab. 2014; 16(11):1165-1173

10. Hong J, Zhang Y, Lai S, et al; SPREAD-DIMCAD Investigators. Effects of metformin versus glipizide on cardiovascular outcomes in patients with type 2 diabetes and coronary artery disease. Diabetes Care. 2013;36(5):1304-1311.

11. Cheng C, Lin CH, Tsai YW, Tsai CJ, Chou PH, Lan TH. Type 2 diabetes and antidiabetic medications in relation to dementia diagnosis. J Gerontol A Biol Sci Med Sci. 2014;69(10):1299-1305.

12. Patel R, Shah G. Effect of metformin on clinical, metabolic and endocrine outcomes in women with polycystic ovary syndrome: a metaanalysis of randomized controlled trials. Curr Med Res Opin. 2017:1-13.

13. Schneider MB, Matsuzaki H, Haorah J, et al. Prevention of pancreatic cancer induction in hamsters by metformin. Gastroenterology. 2001; 120(5):1263-1270.

14. Evans JM, Donnelly LA, Emslie-Smith AM, Alessi DR, Morris AD. Metformin and reduced risk of cancer in diabetic patients. BMJ. 2005, 330(7503):1304-1305.

15. Lee MS, Hsu CC, Wahlqvist ML, Tsai HN, Chang YH, Huang YC. Type 2 diabetes increases and metformin reduces total, colorectal, liver and pancreatic cancer incidences in Taiwanese: a representative population prospective cohort study of 800,000 individuals. BMC Cancer. 2011;11:20.

16. Libby G, Donnelly LA, Donnan PT, Alessi DR, Morris AD, Evans JM. New users of metformin are at low risk of incident cancer: a cohort study among people with type 2 diabetes. Diabetes Care. 2009;32(9): $1620-1625$.
17. Monami M, Colombi C, Balzi D, et al. Metformin and cancer occurrence in insulin-treated type 2 diabetic patients. Diabetes Care. 2011; 34(1):129-131.

18. Landman GW, Kleefstra N, van Hateren KJ, Groenier KH, Gans RO, Bilo HJ. Metformin associated with lower cancer mortality in type 2 diabetes: ZODIAC-16. Diabetes Care. 2010;33(2):322-326.

19. Coyle C, Cafferty FH, Vale C, Langley RE. Metformin as an adjuvant treatment for cancer: a systematic review and meta-analysis. Ann Oncol. 2016;27(12):2184-2195.

20. Bodmer M, Becker C, Meier C, Jick SS, Meier CR. Use of metformin and the risk of ovarian cancer: a case-control analysis. Gynecol Oncol. 2011;123(2):200-204.

21. Tseng $\mathrm{CH}$. Metformin reduces ovarian cancer risk in Taiwanese women with type 2 diabetes mellitus. Diabetes Metab Res Rev. 2015;31(6): 619-626.

22. Jiralerspong S, Palla SL, Giordano SH, et al. Metformin and pathologic complete responses to neoadjuvant chemotherapy in diabetic patients with breast cancer. J Clin Oncol. 2009;27(20):3297-3302.

23. Campagnoli C, Pasanisi $\mathrm{P}, \mathrm{Abbà} \mathrm{C}$, et al. Effect of different doses of metformin on serum testosterone and insulin in non-diabetic women with breast cancer: a randomized study. Clin Breast Cancer. 2012;12(3):175-182.

24. Tseng $\mathrm{CH}$. Metformin significantly reduces incident prostate cancer risk in Taiwanese men with type 2 diabetes mellitus. Eur J Cancer. 2014;50(16):2831-2837.

25. Sehdev A, Shih YC, Vekhter B, Bissonnette MB, Olopade OI, Polite BN. Metformin for primary colorectal cancer prevention in patients with diabetes: a case-control study in a US population. Cancer. 2015;121(7): 1071-1078.

26. Mazzone PJ, Rai H, Beukemann M, Xu M, Jain A, Sasidhar M. The effect of metformin and thiazolidinedione use on lung cancer in diabetics. BMC Cancer. 2012;12:410.

27. Lega IC, Austin PC, Gruneir A, Goodwin PJ, Rochon PA, Lipscombe LL. Association between metformin therapy and mortality after breast cancer: a population-based study. Diabetes Care. 2013;36(10):3018-3026.

28. Margel D, Urbach D, Lipscombe LL, et al. Association between metformin use and risk of prostate cancer and its grade. J Natl Cancer Inst. 2013;105(15):1123-1131.

29. Mc Menamin ÚC, Murray LJ, Hughes CM, Cardwell CR. Metformin use and survival after colorectal cancer: a population-based cohort study. Int J Cancer. 2016;138(2):369-379.

30. Wu L, Zhou B, Oshiro-Rapley N, et al. An ancient, unified mechanism for metformin growth inhibition in C. elegans and cancer. Cell. 2016;167(7):1705-1718.

31. Morales DR, Morris AD. Metformin in cancer treatment and prevention. Anпu Rev Med. 2015;66:17-29.

32. Gallagher EJ, LeRoith D. Diabetes, cancer, and metformin: connections of metabolism and cell proliferation. Ann N Y Acad Sci. 2011;1243:54-68.

33. Draznin B. Mechanism of the mitogenic influence of hyperinsulinemia. Diabetol Metab Syndr. 2011;3(1):10.

34. Ding XZ, Fehsenfeld DM, Murphy LO, Permert J, Adrian TE. Physiological concentrations of insulin augment pancreatic cancer cell proliferation and glucose utilization by activating MAP kinase, PI3 kinase and enhancing GLUT-1 expression. Pancreas. 2000;21(3):310-320.

35. Sachdev D, Yee D. Disrupting insulin-like growth factor signaling as a potential cancer therapy. Mol Cancer Ther. 2007;6(1):1-12.

36. Gong J, Kelekar G, Shen J, Shen J, Kaur S, Mita M. The expanding role of metformin in cancer: an update on antitumor mechanisms and clinical development. Target Oncol. 2016;11(4):447-467.

37. Ma J, Sawai H, Matsuo Y, et al. IGF-1 mediates PTEN suppression and enhances cell invasion and proliferation via activation of the IGF-1/ $\mathrm{PI} 3 \mathrm{~K} /$ Akt signaling pathway in pancreatic cancer cells. J Surg Res. 2010; 160(1):90-101.

38. Algire C, Amrein L, Bazile M, David S, Zakikhani M, Pollak M. Diet and tumor LKB1 expression interact to determine sensitivity to anti-neoplastic effects of metformin in vivo. Oncogene. 2011;30(10):1174-1182.

39. Kourelis TV, Siegel RD. Metformin and cancer: new applications for an old drug. Med Oncol. 2012;29(2):1314-1327. 
40. Dowling RJ, Niraula S, Stambolic V, Goodwin PJ. Metformin in cancer: translational challenges. J Mol Endocrinol. 2012;48(3):R31-R43.

41. Chiang GG, Abraham RT. Targeting the mTOR signaling network in cancer. Trends Mol Med. 2007;13(10):433-442.

42. Yoshida S, Hong S, Suzuki T, et al. Redox regulates mammalian target of rapamycin complex 1 (mTORC1) activity by modulating the TSC1/TSC2-Rheb GTPase pathway. J Biol Chem. 2011;286(37): 32651-32660

43. Inoki K, Zhu T, Guan KL. TSC2 mediates cellular energy response to control cell growth and survival. Cell. 2003;115(5):577-590.

44. Jalving M, Gietema JA, Lefrandt JD, et al. Metformin: taking away the candy for cancer? Eur J Cancer. 2010;46(13):2369-2380.

45. Kalender A, Selvaraj A, Kim SY, et al. Metformin, independent of AMPK, inhibits mTORC1 in a rag GTPase-dependent manner. Cell Metab. 2010;11(5):390-401.

46. Ben Sahra I, Regazzetti C, Robert G, et al. Metformin, independent of AMPK, induces mTOR inhibition and cell-cycle arrest through REDD1. Cancer Res. 2011;71(13):4366-4372.

47. Zhou G, Myers R, Li Y, et al. Role of AMP-activated protein kinase in mechanism of metformin action. J Clin Invest. 2001;108(8):1167-1174.

48. Lettieri Barbato D, Vegliante R, Desideri E, Ciriolo MR. Managing lipid metabolism in proliferating cells: new perspective for metformin usage in cancer therapy. Biochim Biophys Acta. 2014;1845(2):317-324.

49. Ersoy C, Kiyici S, Budak F, et al. The effect of metformin treatment on VEGF and PAI-1 levels in obese type 2 diabetic patients. Diabetes Res Clin Pract. 2008;81(1):56-60.

50. Hirsch HA, Iliopoulos D, Struhl K. Metformin inhibits the inflammatory response associated with cellular transformation and cancer stem cell growth. Proc Natl Acad Sci U S A. 2013;110(3):972-977.

51. Eikawa S, Nishida M, Mizukami S, Yamazaki C, Nakayama E, Udono H. Immune-mediated antitumor effect by type 2 diabetes drug, metformin. Proc Natl Acad Sci U S A. 2015;112(6):1809-1814.

52. Christensen K, Doblhammer G, Rau R, Vaupel JW. Ageing populations: the challenges ahead. Lancet. 2009;374(9696):1196-1208.

53. Cabreiro F, Au C, Leung KY, et al. Metformin retards aging in C. elegans by altering microbial folate and methionine metabolism. Cell. 2013;153(1):228-239.

54. Martin-Montalvo A, Mercken EM, Mitchell SJ, et al. Metformin improves healthspan and lifespan in mice. Nat Commun. 2013;4:2192.

55. Anisimov VN, Berstein LM, Popovich IG, et al. If started early in life, metformin treatment increases life span and postpones tumors in female SHR mice. Aging (Albany NY). 2011;3(2):148-157.

56. Effect of intensive blood-glucose control with metformin on complications in overweight patients with type 2 diabetes (UKPDS 34). UK Prospective Diabetes Study (UKPDS) Group. Lancet. 1998;352(9131): 854-865.

57. Wu JW, Boudreau DM, Park Y, Simonds NI, Freedman AN. Commonly used diabetes and cardiovascular medications and cancer recurrence and cancer-specific mortality: a review of the literature. Expert Opin Drug Saf. 2014;13(8):1071-1099.

58. Slack C, Foley A, Partridge L. Activation of AMPK by the putative dietary restriction mimetic metformin is insufficient to extend lifespan in Drosophila. PLoS One. 2012;7(10):e47699.

59. Longo VD, Antebi A, Bartke A, et al. Interventions to slow aging in humans: are we ready? Aging Cell. 2015;14(4):497-510.

60. Liu B, Fan Z, Edgerton SM, Yang X, Lind SE, Thor AD. Potent antiproliferative effects of metformin on trastuzumab-resistant breast cancer cells via inhibition of erbB2/IGF-1 receptor interactions. Cell Cycle. 2011;10(17):2959-2966.

61. Bridges HR, Jones AJ, Pollak MN, Hirst J. Effects of metformin and other biguanides on oxidative phosphorylation in mitochondria. Biochem J. 2014;462(3):475-487.

62. Zheng Z, Chen H, Li J, et al. Sirtuin 1-mediated cellular metabolic memory of high glucose via the LKB1/AMPK/ROS pathway and therapeutic effects of metformin. Diabetes. 2012;61(1):217-228.

63. Lien F, Berthier A, Bouchaert E, et al. Metformin interferes with bile acid homeostasis through AMPK-FXR crosstalk. J Clin Invest. 2014; 124(3):1037-1051.
64. Lu J, Shi J, Li M, et al. Activation of AMPK by metformin inhibits TGF-beta-induced collagen production in mouse renal fibroblasts. Life Sci. 2015;127:59-65.

65. Duca FA, Côté CD, Rasmussen BA, et al. Metformin activates a duodenal Ampk-dependent pathway to lower hepatic glucose production in rats. Nat Med. 2015;21(5):506-511.

66. Nair V, Sreevalsan S, Basha R, et al. Mechanism of metformindependent inhibition of mammalian target of rapamycin (mTOR) and Ras activity in pancreatic cancer: role of specificity protein $(\mathrm{Sp})$ transcription factors. J Biol Chem. 2014;289(40):27692-27701.

67. Pérez-Revuelta BI, Hettich MM, Ciociaro A, et al. Metformin lowers Ser-129 phosphorylated alpha-synuclein levels via mTOR-dependent protein phosphatase 2A activation. Cell Death Dis. 2014;5:e1209.

68. Saisho Y. Metformin and inflammation: its potential beyond glucoselowering effect. Endocr Metab Immune Disord Drug Targets. 2015; 15(3):196-205.

69. Song YM, Lee YH, Kim JW, et al. Metformin alleviates hepatosteatosis by restoring SIRT1-mediated autophagy induction via an AMP-activated protein kinase-independent pathway. Autophagy. 2015;11(1):46-59.

70. Benjamin EJ, Blaha MJ, Chiuve SE, et al; American Heart Association Statistics Committee and Stroke Statistics Subcommittee. Heart disease and stroke statistics-2017 update: a report from the American Heart Association. Circulation. 2017;135(10):e146-e603.

71. Holman RR, Paul SK, Bethel MA, Matthews DR, Neil HA. 10-Year follow-up of intensive glucose control in type 2 diabetes. $N$ Engl J Med. 2008;359(15):1577-1589.

72. Roumie CL, Hung AM, Greevy RA, et al. Comparative effectiveness of sulfonylurea and metformin monotherapy on cardiovascular events in type 2 diabetes mellitus: a cohort study. Ann Intern Med. 2012;157(9): 601-610.

73. Roussel R, Travert F, Pasquet B, et al; Reduction of Atherothrombosis for Continued Health (REACH) Registry Investigators. Metformin use and mortality among patients with diabetes and atherothrombosis. Arch Intern Med. 2010;170(21):1892-1899.

74. Xu T, Brandmaier S, Messias AC, et al. Effects of metformin on metabolite profiles and LDL cholesterol in patients with type 2 diabetes. Diabetes Care. 2015;38(10):1858-1867.

75. Seifarth C, Schehler B, Schneider HJ. Effectiveness of metformin on weight loss in non-diabetic individuals with obesity. Exp Clin Endocrinol Diabetes. 2013;121(1):27-31.

76. Fontbonne A, Diouf I, Baccara-Dinet M, Eschwege E, Charles MA. Effects of 1-year treatment with metformin on metabolic and cardiovascular risk factors in non-diabetic upper-body obese subjects with mild glucose anomalies: a post-hoc analysis of the BIGPRO1 trial. Diabetes Metab. 2009;35(5):385-391.

77. Malin SK, Nightingale J, Choi SE, Chipkin SR, Braun B. Metformin modifies the exercise training effects on risk factors for cardiovascular disease in impaired glucose tolerant adults. Obesity (Silver Spring). 2013; 21(1):93-100.

78. Adeyemo MA, McDuffie JR, Kozlosky M, et al. Effects of metformin on energy intake and satiety in obese children. Diabetes Obes Metab. 2015;17(4):363-370.

79. Zhou L, Liu H, Wen X, Peng Y, Tian Y, Zhao L. Effects of metformin on blood pressure in nondiabetic patients: a meta-analysis of randomized controlled trials. J Hypertens. 2017;35(1):18-26.

80. Thomopoulos C, Katsimagklis G, Makris T. Metformin and blood pressure lowering: a questioned association. J Hypertens. 2017;35(1):27-28.

81. Wan X, Huo Y, Johns M, et al. 5'-AMP-activated protein kinaseactivating transcription factor 1 cascade modulates human monocytederived macrophages to atheroprotective functions in response to heme or metformin. Arterioscler Thromb Vasc Biol. 2013;33(11): 2470-2480.

82. Isoda K, Young JL, Zirlik A, et al. Metformin inhibits proinflammatory responses and nuclear factor-kappaB in human vascular wall cells. Arterioscler Thromb Vasc Biol. 2006;26(3):611-617.

83. Ng TP, Feng L, Yap KB, Lee TS, Tan CH, Winblad B. Long-term metformin usage and cognitive function among older adults with diabetes. J Alzheimers Dis. 2014;41(1):61-68. 
84. Herath PM, Cherbuin N, Eramudugolla R, Anstey KJ. The effect of diabetes medication on cognitive function: evidence from the PATH through life study. Biomed Res Int. 2016;2016:7208429.

85. Guo M, Mi J, Jiang QM, et al. Metformin may produce antidepressant effects through improvement of cognitive function among depressed patients with diabetes mellitus. Clin Exp Pharmacol Physiol. 2014; 41(9):650-656.

86. Luchsinger JA, Perez T, Chang H, et al. Metformin in amnestic mild cognitive impairment: results of a pilot randomized placebo controlled clinical trial. J Alzheimers Dis. 2016;51(2):501-514.

87. Imfeld P, Bodmer M, Jick SS, Meier CR. Metformin, other antidiabetic drugs, and risk of Alzheimer's disease: a population-based case-control study. J Am Geriatr Soc. 2012;60(5):916-921.

88. Moore EM, Mander AG, Ames D, et al; AIBL Investigators. Increased risk of cognitive impairment in patients with diabetes is associated with metformin. Diabetes Care. 2013;36(10):2981-2987.

89. Kickstein E, Krauss S, Thornhill P, et al. Biguanide metformin acts on tau phosphorylation via mTOR/protein phosphatase 2A (PP2A) signaling. Proc Natl Acad Sci U S A. 2010;107(50):21830-21835.

90. Li J, Deng J, Sheng W, Zuo Z. Metformin attenuates Alzheimer's disease-like neuropathology in obese, leptin-resistant mice. Pharmacol Biochem Behav. 2012;101(4):564-574.

91. Picone P, Nuzzo D, Caruana L, et al. Metformin increases APP expression and processing via oxidative stress, mitochondrial dysfunction and NF-kappaB activation: use of insulin to attenuate metformin's effect. Biochim Biophys Acta. 2015;1853(5):1046-1059.

92. Hettich MM, Matthes F, Ryan DP, et al. The anti-diabetic drug metformin reduces BACE1 protein level by interfering with the MID1 complex. PLoS One. 2014;9(7):e102420.

93. Poels J, Spasić MR, Callaerts P, Norga KK. Expanding roles for AMPactivated protein kinase in neuronal survival and autophagy. Bioessays. 2009;31(9):944-952.

94. Jin Q, Cheng J, Liu Y, et al. Improvement of functional recovery by chronic metformin treatment is associated with enhanced alternative activation of microglia/macrophages and increased angiogenesis and neurogenesis following experimental stroke. Brain Behav Immun. 2014;40:131-142.

95. Jiang T, Yu JT, Zhu XC, et al. Acute metformin preconditioning confers neuroprotection against focal cerebral ischaemia by pre-activation of AMPK-dependent autophagy. Br J Pharmacol. 2014;171(13): 3146-3157.

96. Venna VR, Li J, Hammond MD, Mancini NS, McCullough LD. Chronic metformin treatment improves post-stroke angiogenesis and recovery after experimental stroke. Eur J Neurosci. 2014;39(12): 2129-2138.

97. Pintana H, Apaijai N, Pratchayasakul W, Chattipakorn N, Chattipakorn SC. Effects of metformin on learning and memory behaviors and brain mitochondrial functions in high fat diet induced insulin resistant rats. Life Sci. 2012;91(11-12):409-414.

98. Zhao RR, Xu XC, Xu F, et al. Metformin protects against seizures, learning and memory impairments and oxidative damage induced by pentylenetetrazole-induced kindling in mice. Biochem Biophys Res Commun. 2014;448(4):414-417.

99. Alzoubi KH, Khabour OF, Al-Azzam SI, Tashtoush MH, Mhaidat NM. Metformin eased cognitive impairment induced by chronic 1-methionine administration: potential role of oxidative stress. Curr Neuropharmacol. 2014;12(2):186-192.
100. Chen F, Dong RR, Zhong KL, et al. Antidiabetic drugs restore abnormal transport of amyloid-beta across the blood-brain barrier and memory impairment in db/db mice. Neuropharmacology. 2016;101: 123-136.

101. Guzick D. Polycystic ovary syndrome: symptomatology, pathophysiology, and epidemiology. Am J Obstet Gynecol. 1998;179(6 Pt 2): S89-S93.

102. Pasquali R, Stener-Victorin E, Yildiz BO, et al. PCOS Forum: research in polycystic ovary syndrome today and tomorrow. Clin Endocrinol (Oxf). 2011;74(4):424-433.

103. Carmina E, Lobo RA. Use of fasting blood to assess the prevalence of insulin resistance in women with polycystic ovary syndrome. Fertil Steril. 2004;82(3):661-665.

104. Dunaif A. Insulin resistance and the polycystic ovary syndrome: mechanism and implications for pathogenesis. Endocr Rev. 1997; 18(6):774-800.

105. Ovalle F, Azziz R. Insulin resistance, polycystic ovary syndrome, and type 2 diabetes mellitus. Fertil Steril. 2002;77(6):1095-1105.

106. Moran LJ, Misso ML, Wild RA, Norman RJ. Impaired glucose tolerance, type 2 diabetes and metabolic syndrome in polycystic ovary syndrome: a systematic review and meta-analysis. Hum Reprod Update. 2010;16(4):347-363.

107. Lim SS, Davies MJ, Norman RJ, Moran LJ. Overweight, obesity and central obesity in women with polycystic ovary syndrome: a systematic review and meta-analysis. Hum Reprod Update. 2012;18(6): 618-637.

108. de Groot PC, Dekkers OM, Romijn JA, Dieben SW, Helmerhorst FM. PCOS, coronary heart disease, stroke and the influence of obesity: a systematic review and meta-analysis. Hum Reprod Update. 2011;17(4): 495-500.

109. Wild S, Pierpoint T, McKeigue P, Jacobs H. Cardiovascular disease in women with polycystic ovary syndrome at long-term follow-up: a retrospective cohort study. Clin Endocrinol (Oxf). 2000;52(5):595-600.

110. Velazquez EM, Mendoza S, Hamer T, Sosa F, Glueck CJ. Metformin therapy in polycystic ovary syndrome reduces hyperinsulinemia, insulin resistance, hyperandrogenemia, and systolic blood pressure, while facilitating normal menses and pregnancy. Metabolism. 1994; 43(5):647-654

111. Moghetti P, Castello R, Negri C, et al. Metformin effects on clinical features, endocrine and metabolic profiles, and insulin sensitivity in polycystic ovary syndrome: a randomized, double-blind, placebocontrolled 6-month trial, followed by open, long-term clinical evaluation. J Clin Endocrinol Metab. 2000;85(1):139-146.

112. Glueck CJ, Wang P, Fontaine R, Tracy T, Sieve-Smith L. Metformin to restore normal menses in oligo-amenorrheic teenage girls with polycystic ovary syndrome (PCOS). J Adolesc Health. 2001;29(3): 160-169.

113. Tang T, Lord JM, Norman RJ, Yasmin E, Balen AH. Insulin-sensitising drugs (metformin, rosiglitazone, pioglitazone, D-chiro-inositol) for women with polycystic ovary syndrome, oligo amenorrhoea and subfertility. Cochrane Database Syst Rev. 2012;5:CD003053.

114. Shi Q, Liu S, Fonseca V, Shi L. 72-OR / 72 - The effect of metformin exposure on neurodegenerative disease among elder adult veterans with diabetes mellitus. Abstract presented at: Proceedings of the American Diabetes Association 76th Scientific Sessions; June 10-14; 2016; New Orleans, LA.

Drug Design, Development and Therapy

\section{Publish your work in this journal}

Drug Design, Development and Therapy is an international, peerreviewed open-access journal that spans the spectrum of drug design and development through to clinical applications. Clinical outcomes, patient safety, and programs for the development and effective, safe, and sustained use of medicines are the features of the journal, which

Submit your manuscript here: http://www.dovepress.com/drug-design-development-and-therapy-journal

has also been accepted for indexing on PubMed Central. The manuscript management system is completely online and includes a very quick and fair peer-review system, which is all easy to use. Visit http://www.dovepress.com/testimonials.php to read real quotes from published authors.

\section{Dovepress}

Submit your manuscript here: http//wwwdovepress.com/drug-design-develophent-and-therapyjoural 